\title{
SCANNING ELECTRON MICROSCOPY OF MICROTETRAMERES SPIRALIS (NEMATODA, FAMILY TETRAMERIDAE) PARASITISING CATTLE EGRET "ARDEOLA IBIS IBIS" IN EGYPT
}

\author{
Hewaydah E. Abou Shafeey* \\ Department of Zoology, Faculty of Science, Tanta University, Gharbia, Egypt
}

\begin{abstract}
Article History:
Received: 04 November 2019

Revised: 29 November 2019

Accepted: 29 November 2019

Published Online:

5 December 2019

Keywords:

Ardeola ibis ibis

Microtetrameres spiralis

Nematodes

Proventriculus

Scanning electron microscopy

*Correspondence:

Hewaydah Abou Shafeey

Zoology Department

Faculty of Science

Tanta University

Gharbia, Egypt

E-mail:

hewaydah@yahoo.com
\end{abstract}

\begin{abstract}
Microtetrameres spiralis is one of the common spirurid parasites recovered from the cattle egret "Ardeola ibis ibis". No data was available on its ultrastructural characteristics with scanning electron microscopy. Therefore, the present study aimed to investigate, in details, the characteristic features of $M$. spiralis in cattle egret using both the light and scanning electron microscopies. The results revealed that nine out of seventeen Ardeola ibis ibis (53\%) were infected with M. spiralis. Female worms were deeply embedded in proventriculus wall; their bodies were twisted in longitudinal tight spiral forming 2-3 turns. Males move in lumen; sometimes they were lodged on lining. They have filiform cylindrical shape. Male possesses two unequal and dissimilar spicules. The buccal capsule is well-chitinized, thick-walled, flask-shaped in females, but tubular in males. The vulva lies at the posterior third of the body. Cuticle was sharp transverse annulated along whole length of the body without alae or spines. Each pseudolabium has inner and outer edges; the outer edge has wavy-shaped, triple swollen processes. The depressed part that located between the two edges of each pseudolabium contained three corrugated, flower-shaped processes. The anterior annulations are ridged and have numerous pointed triangular processes. A single raised corrugated papilla appeared. Buttonlike structures are distributed on longitudinal striations. An oval striated, papilla-shaped structure is elevated with coiled, rodshaped projection. The transverse annulations over the midportion of the female's body have wavy margins.
\end{abstract}

\section{INTRODUCTION}

Egypt is perfect transit for migratory birds, due to its miscellaneous habitats and temperate weather. Cattle egret, buff-backed heron "Ardeola ibis ibis", is a cosmopolitan wild bird species of family Ardeidae that lives in agricultural lands ${ }^{[1]}$. The cattle egret is popular for its role in the biocontrol of cattle parasites, land pests, agricultural insects, mollusks, and earthworms. Wild birds constitute a possible risk for domestic species and human being due to spreading of parasitic infections ${ }^{[2]}$. These birds feed on arthropods, mollusks, fishes, reptiles, and rodents, which many of them act as intermediate host for helminths ${ }^{[3]}$. In natural infection, the wild birds are found associated with the severe damage of gizzard and 
proventriculus $^{[4]}$. Heavy infestation with these parasites may result in death of the host ${ }^{[5]}$. In addition, these parasites caused great economic losses through decreasing feed efficiency and weight gain, as well as delaying sexual maturity and egg production $^{[6]}$. In Egypt, different helminthic parasites of cattle egrets were studied ${ }^{[7-14]}$.

The family Tetrameridae (Nematoda) is characterized by the sexual dimorphism of the species. The body shape pattern of the female is the main characteristic key used to differentiate between genera of the family ${ }^{[15]}$. The most commonly reported parasites of herons (egrets) are tetramerid spirurid nematodes. Both subgenera Tetrameres and Microtetrameres were raised to generic category based on female body form; globular or spindle-shaped in Tetrameres and with its longitudinal axis spirally coiled in Microtetrameres ${ }^{[15]}$. The genus Microtetrameres currently includes several species parasitic in birds worldwide ${ }^{[1,3,16-19]}$. In the agricultural country like Egypt; man is usually in close interaction with water, therefore there is a potential danger of invasion with nematodes of birds. Microtetrameres spiralis is one of the common tetramerid nematode parasites that were previously reported from the Egyptian Ardeola ibis ibis; but inadequately described (with no morphological data for the females) $[1,20]$. The morphological description of the microtetramerid nematodes by scanning electron microscope (SEM) is lacking. Therefore, the present study was conducted to investigate, in details, the characteristic features of $M$. spiralis in comparison with previous reports using both light microscope and SEM.

\section{MATERIAL AND METHODS Collection of specimens}

The proventriculus of seventeen Ardeola ibis ibis collected from Gharbia Governorate was examined for parasitic infection by the light microscopy. Nematodes were collected by light pressure on the proventriculus wall around the swollen lesions for collecting the female specimens. Male specimens were collected from the mucus of the proventricular lumen and from beneath the lining of the proventriculus.

\section{Light microscopy}

The collected specimens washed in normal saline $0.7 \%$. Female and male specimens fixed in $70 \%$ ethanol, cleared in lactophynol and mounted in glycerine jelly. Mounted specimens were photographed using an Olympus C X 31 microscope and an Olympus imaging corp digital camera E-330 DC 7.4 V (Olympus MEA FZ-LLC, Dubai, UAE). The morphometric studies were based on randomly selected 40 specimens (20 males and 20 females) and measured by $0.01 \mathrm{~mm}$ microscope micrometre glass scale (PZO, Warszawa, Poland) and a calibrated lens.

\section{Scanning electron microscopy}

Specimens were fixed in $3 \%$ phosphate buffered glutaraldehyde, post fixed in $1 \%$ osmium tetroxide, critical point-dried using the EMS 850 Critical Point Dryer (Electron Microscopy Sciences, Hatfield, PA, USA). Specimens were gold-coated (nearly $50 \mathrm{~nm}$ thickness) using an SPI Module $^{\mathrm{TM}}$ Sputter Coater System (West Chester, PA, USA), and then examined and photographed using the high-vacuum mode of a JEOL JSM-5500LV SEM (Tokyo, Japan) at an accelerating voltage of $25 \mathrm{KV}$. SEM examination was based on 12 specimens, 4 males and 8 females.

\section{RESULTS}

\section{Rate of natural infection}

The examination of 17 birds (10 females and 7 males) revealed that nine $(53 \%)$ were naturally-infected with tetramerid nematodes $M$. spiralis inhabiting the proventriculus, which also contained parts of insects and frogs among other food debris (Figure 1a). The nine infected birds were five females (29\%) and four males (24\%).

\section{Parasite description by light and scanning electron microscopy}

The light microscopic examination of proventriculus revealed that the females of 
M. spiralis were found deeply embedded in proventriculus wall (within the gastric glands) with suspended tails in the lumen of the proventriculus forming numerous swollen lesions (Figure 1a). The collected live adult females were bright red in colour and their bodies were twisted in longitudinal tight spiral, forming of two to three turns. The anterior and posterior ends protruded from the central portion and wrapped around body. Both ends are gradually pointed (Figures $1 \mathrm{~b}$ and $\mathrm{c}$ ). The female measured $3.3-3.8 \mathrm{~mm}$ in length, while the swollen globular mass of mid-portion of the body measured 0.863-1.099 $\mathrm{mm}$ in the diameter (Table 1). The anterior end has a small mouth that leads into a small, chitinous, thickwalled, and flask-shaped buccal capsule (Figures 1d and e), which measured 0.023$0.029 \mathrm{~mm}$ in length and $0.019-0.021 \mathrm{~mm}$ in width (Table 1). Gut is tubular with oesophagus composed of muscular part and glandular part. The muscular part of oesophagus (Figure 1d) measured 0.238$0.283 \mathrm{~mm}$ in length and $0.029-0.035 \mathrm{~mm}$ in width (Table 1). Meanwhile, the glandular oesophagus could not be measured correctly due to the corrugation of the specimens. The intestine is usually filled with detritus and ends in a narrow tube opening at the anus. The intestine appeared brown or black in colour (Figures $1 \mathrm{~b}$ and $\mathrm{c}$ ). Anal opening lies just posterior to the vulva at the distance of $0.204-0.238 \mathrm{~mm}$ from posterior tip of the tail (Figure 1f). The gravid females contain coiled uterus filled with enormous embryonated mature eggs. The eggs measured $0.036-0.051 \mathrm{~mm}$ in length and 0.017 $0.032 \mathrm{~mm}$ in width (Table 1). Eggs are transparent, thick shelled and wide elongated with rounded ends, while their sides have one more flattened than other. The eggs contained fully developed embryo, which appeared as banana-like structure without seeming any movement (Figures $1 \mathrm{~g}$ and $\mathrm{h}$ ). The vulva lies a short distance in front of anus at $0.190-0.314 \mathrm{~mm}$ anterior to the anal opening (Table 1). The posterior extremity showed gradually elongated sharp end, with a long pointed rod-shaped structure that may be withdrawn within the tail cuticle (Figure 1f).

Scanning electron micrographs of female $M$. spiralis showed that the buccal opening of the female appeared hexagonal in shape and surrounded with two pseudolabia with inner and outer edges; in between the two edges of each pseudolabium a depressed part was located. The outer edge has triple swollen (wavy-shaped) processes; and it is more elevated than the inner one, which also has triple wavy-shaped, but less swollen. The depressed part that located between the two edges of each pseudolabium contained three corrugated flower-shaped, regularly-distributed processes (Figure 2a). Each pseudolabium bears a single amphid and a pair of rounded pedunculated cephalic papillae (Figure 2a). Body of each papilla appeared longitudinally striated sides with a smooth cover (Figure 2b). The scanning electron micrographs illustrated that the cuticle was sharp transverse annulated along the whole length of the body without alae or cuticular spines. The cuticle over the globular mid-portion of the body was most deeply transverse annulated with wavy margins (Figure 2c). In the anterior part, the transverse annulations gradually appear slightly ridged and show numerous irregularly distributed, short pointed, triangular processes. A single raised corrugated papilla was obviously appeared (Figure 2d). The regular, parallel, longitudinally striations were obviously detected anteriorly in between the cuticular transverse striations. At higher magnification, small bulges raised button-like structures are irregularly distributed on the longitudinal striations in between transverse ones. An oval striated, papilla-shaped structure is elevated in between these longitudinal striations with small coiled rod-shaped projection in its centre (Figure 2e). Female posterior end is curved ventrally and showed numerous wide transverse pleats that lead to short flat collar-like part. The collar-like part leads to another long pointed part that has a tiny pointed tip (Figure $2 \mathrm{f}$ ). 

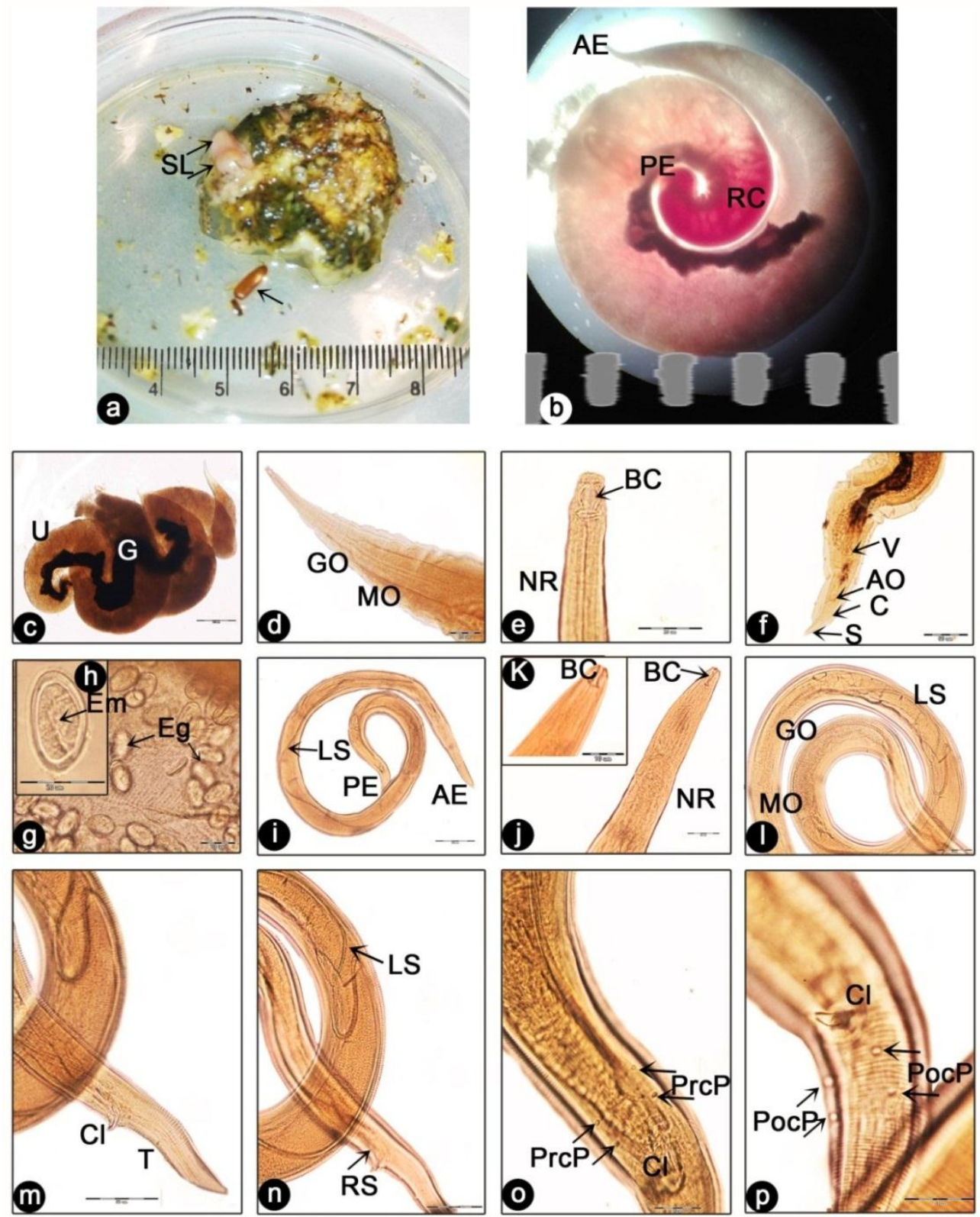

Figure 1: Photomicrographs of the proventriculus of Ardeola ibis ibis (a), female (b-g) and male (i-p) of Microtetrameres spiralis. (a) Enlarged part of the proventriculus showing part of insect (arrow), swollen lesions (SL). (b) Apical view of female specimen showing red colour (RC), anterior end (AE), and posterior end (PE). (c) Lateral view of spirally coiled female specimen (three body turns) showing the uterus (U) and gut (G). (d and e) High magnification of anterior part of female specimen showing glandular oesophagus (GO), muscular oesophagus (MO), buccal capsule (BC), and nerve ring (NR). (f) Posterior extremity of female specimen showing pointed structure (S), tail cuticle $(\mathrm{C})$, vulva (V), anal opening (AO). (g) Enlarged part of the uterus showing eggs (Eg). (h) High magnification of an egg contained fully developed embryo (Em). (i) Male specimen, left spicule (LS). $(\mathbf{j}-\ell)$ High magnification of the anterior end of male specimen. (m) Caudal end of the male specimen, tail region $(\mathrm{T})$, cloaca $(\mathrm{Cl})$. (n) Venterolateral view of posterior extremity of the male specimen showing flexed left spicule (LS) and right spicule (RS). (o) Ventral view of enlarged caudal part showing precloacal papillae (PrcP). (p) Ventral view of enlarged caudal part showing postcloacal papillae (PocP). Scale bar: $10 \mu \mathrm{m}$ (g and k), $20 \mu \mathrm{m}$ (d, e, h, j, $\mathbf{o}$, and $\mathbf{p}$ ), $50 \mu \mathrm{m}$ (f and $\ell-\mathbf{n}), 100 \mu \mathrm{m}$ (c and i), $1000 \mu \mathrm{m}$ (b). 
Table 1: Comparative measurements $(\mathrm{mm})$ of females Microtetrameres spiralis detected in Egypt.

\begin{tabular}{lll}
\hline & \multicolumn{1}{c}{$\begin{array}{c}\text { Microtetrameres spiralis } \\
\text { (Mahdy and El-Ghaysh }{ }^{[1]} \text { ) }\end{array}$} & \multicolumn{1}{c}{$\begin{array}{c}\text { Microtetrameres spiralis } \\
\text { (current study) }\end{array}$} \\
\cline { 2 - 3 } Host & $\begin{array}{l}\text { Ardeola ibis ibis } \\
\text { Locality }\end{array}$ & $\begin{array}{l}\text { Ardeola ibis ibis } \\
\text { Aody length }\end{array}$ \\
Body width & $3.1-3.6$ & $3.3-3.8$ \\
Buccal capsule length & ND & $0.863-1.099$ \\
Muscular oesophagus length & $0.021-0.03$ & $0.023-0.029$ \\
Oesophagus width & ND & $0.238-0.283$ \\
Eggs length & ND & $0.029-0.035$ \\
Eggs width & 0.033 & $0.036-0.051$ \\
Vulva & 0.016 & $0.017-0.032$ \\
& Anterior third of & Posteriorly \\
Tail length & the body & (distance to anus $0.190-0.314)$ \\
\hline
\end{tabular}

ND: not determined

The cuticle over the posterior end showed finely delicate cuticular transverse striations (Figures $2 \mathrm{~g}$ and $\mathrm{h}$ ) of collar-like part from which projected the caudal conical extremity. The cuticle of the posterior tip was inflated, where the higher magnification showed the cuticular transverse striations are gradually merged into irregular corrugations (Figure 2i).

The light microscopic examination revealed that the males of $M$. spiralis apparently moved freely in the lumen of the proventriculus; sometimes few males were lodged on the lining or occurred in the mucus of the proventricular lumen. Males were medium-sized, whitish in colour, and filiform, cylindrical in shape. Their body was stout and curled ventrally towards the posterior end (Figure 1i). Male body length was $3.3-4.2 \mathrm{~mm}$, and the width at about their middle part was 0.11-0.14 mm (Table 2). The mouth leads into a small, well chitinized, thick-walled, and tubular buccal capsule; $0.19-0.29 \mathrm{~mm}$ in length (Table 2) and 0.009-0.008 mm in diameter (Figures $1 \mathrm{j}$ and $\mathrm{k}$ ). The oesophagus was clearly divided into two regions, an anterior muscular and a posterior glandular parts (Figures $1 \mathrm{j}$ and $\ell$ ). The length of the muscular part of oesophagus measured $0.268-0.393 \mathrm{~mm}$, while its width measured $0.032-0.038 \mathrm{~mm}$ at the middle part of the body (Table 2). It is encircled by the nerve ring about $0.133-0.146 \mathrm{~mm}$ from the anterior end (Table 2). The length of the glandular oesophagus measured $0.353-0.471 \mathrm{~mm}$, and its width measured $0.046-0.058 \mathrm{~mm}$ (Table 2). The caudal end of the male worms is ventrally curved. The tail is elongated, non-alate, and conical in shape; it measured $0.228-0.247 \mathrm{~mm}$ in length (Table 2), and gradually pointed extremity with rounded tip (Figures 1i and $\mathrm{m}$ ). Each male possesses two spicules, very unequal in length and dissimilar in shape. The left spicule is well chitinized and slender; its proximal and distal terminations are slightly rounded. It is remarkably long, extending anteriorly, and when not extruded it flexed and recur internally near the male mid-body (Figures $1 l$ and $n$ ). Its proximal termination is situated just behind the end of the oesophagus and measuring 2.292-2.748 mm in length (Table 2). The right spicule is less heavily chitinized, short arcuate, and not easily obvious (Figure 1n); it measured 0.139-0.173 mm in length (Table 2). 

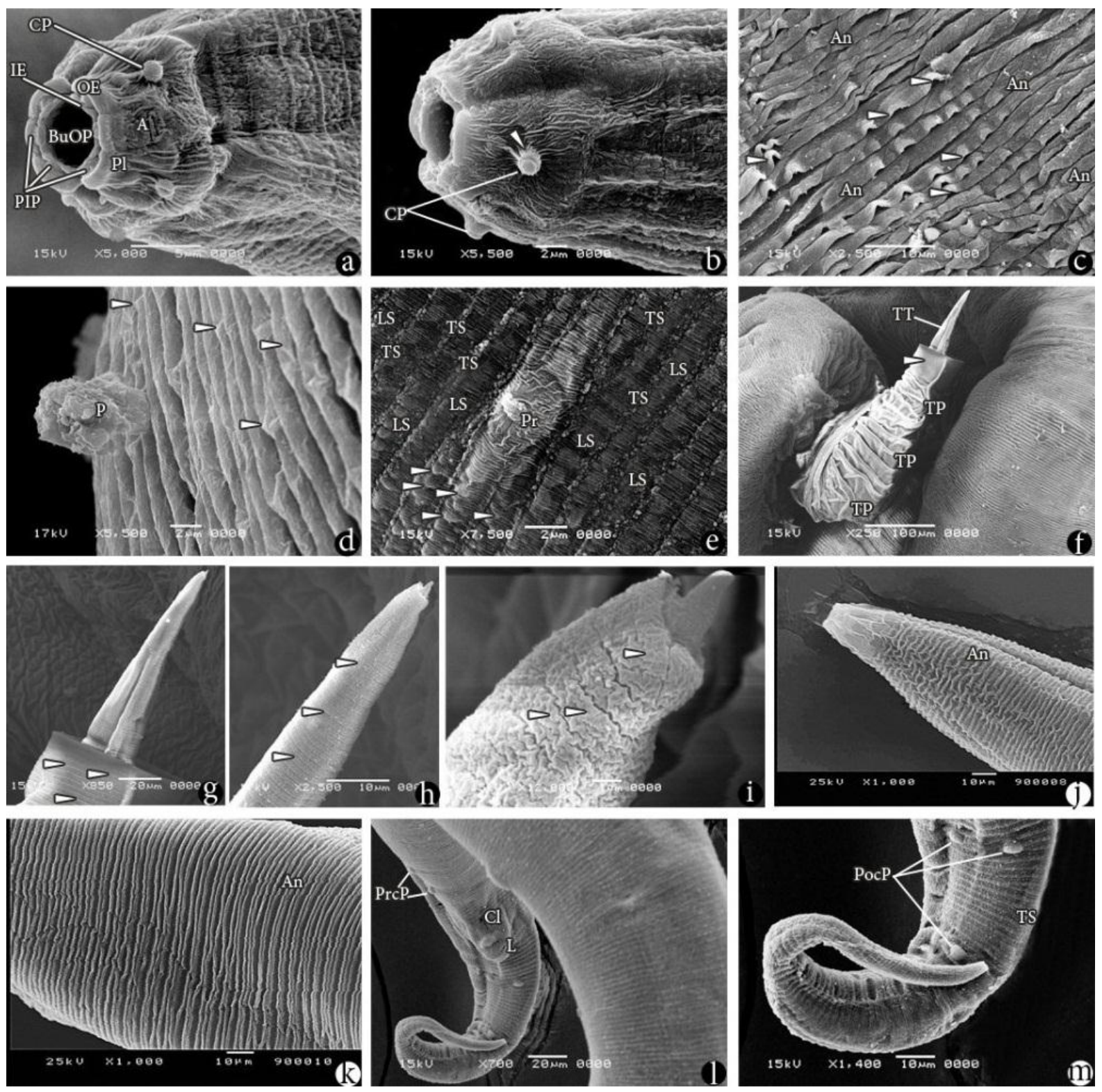

Figure 2: Scanning electron micrographs of female (a-i) and male (j-m) of Microtetrameres spiralis. (a) Subapical view of the anterior end of female specimen showing the buccal opening (BuOp), two pseudolabia (Pl), outer edge (OE), inner edge (IE), pseudolabia processes (PIP), cephalic papillae (CP), and an amphid (A). (b) Lateral view of the anterior end showing the longitudinally striated stalk (arrowhead) of the cephalic papillae (CP). (c) Female mid-body cuticle showing transverse annulations (An) and wavy margins (arrowheads). (d) High magnification of annulations showing triangular processes (arrowheads) and corrugated papilla (P). (e) Cuticular transverse striations (TS) of the anterior part of the body, longitudinally striations (LS), projection (Pr), and bulges (arrowheads). (f) Posterior extremity showing curved tail with transverse pleats (TP), collarlike part (arrowhead), tail tip (TT). (g and h) Enlarged posterior extremity of collar-like part showing cuticular transverse striations (arrowheads). (i) High magnification of female tail posterior tip showing cuticular corrugations (arrowheads). (j) Anterior part of male specimen showing cuticular transverse annulations (An). (k) Enlarged cuticular transverse annulations (An) near middle male body part. (l) Posterior part of male showing cloaca (Cl), lips (L), and precloacal papillae (PrcP). (m) Higher magnification of male posterior part showing delicate transverse striations (TS), towards the posterior tip, and postcloacal papillae (PocP). 
Table 2: Comparative measurements $(\mathrm{mm})$ of males Microtetrameres spiralis detected in Egypt.

\begin{tabular}{lll}
\hline & \multicolumn{1}{c}{$\begin{array}{c}\text { Microtetrameres spiralis } \\
\left(\text { Mahdy and El-Ghaysh }{ }^{[1]}\right)\end{array}$} & $\begin{array}{c}\text { Microtetrameres spiralis } \\
\text { (current study) }\end{array}$ \\
\cline { 2 - 3 } Host & $\begin{array}{l}\text { Ardeola ibis ibis } \\
\text { Abo-Rawash, Giza province }\end{array}$ & $\begin{array}{l}\text { Ardeola ibis ibis } \\
\text { Locality }\end{array}$ \\
Body length & $4.0-4.2$ & $3.3-4.2$ \\
Body width & ND & $0.11-0.14$ \\
Buccal capsule length & $0.17-0.21$ & $0.19-0.29$ \\
Muscular oesophagus length & ND & $0.268-0.393$ \\
Muscular oesophagus width & ND & $0.032-0.038$ \\
Glandular oesophagus length & ND & $0.353-0.471$ \\
Glandular oesophagus width & ND & $0.046-0.058$ \\
Nerve ring & ND & $0.133-0.146$ \\
Left spicule length & $2.2-2.5$ (simple tip) & $2.292-2.748$ \\
Right spicule length & $0.13-0.15$ (point tip) & $0.139-0.173$ \\
Left/right spicule ratio & $16: 1$ & $16: 1$ \\
Tail length & $0.23-0.28$ & $0.228-0.247$ \\
No. of precloacal papillae & 3 & 2 pairs \\
No. of postcloacal papillae & 3 & 2 pairs \\
\hline
\end{tabular}

ND: not determined, No.: number

The left/right spicule ratio is 16:1. Each male possesses four pairs of sessile genital papillae near the cloacal aperture, two pairs precloacal and two pairs postcloacal; ventrally bilaterally symmetrical (Figure 1p).

Scanning electron micrographs of male $M$. spiralis showed that the deeply cuticular transverse annulations appeared along the length of the body (Figures $2 \mathrm{j}$ and $\mathrm{k}$ ). The cloaca has protuberant, elevated lips with elongated aperture; the cuticle of lips is irregularly corrugated (Figure 2l). Precloacal and postcloacal papillae appeared sessile, oval in shape. The cuticular annulations appeared as delicate striations towards the posterior tip (Figure $2 \mathrm{~m}$ ).

\section{DISCUSSION}

The present study elucidated one tetramerid worm that invaded the buff-backed heron (Ardeola ibis ibis). The described nematode was assigned to the genus Microtetrameres depending on the body of the female (twisted in tight) and male (without spines on lateral sides). The identification based on this criterion agrees with other studies that adopted and considered Microtetrameres as a separate genus ${ }^{[15,21-25]}$. The presence of some parts of insects' bodies within the proventricular cavity of the buff-backed heron in the current and previous studies ${ }^{[3]}$ proved that different insect species played a role in the transmission of $M$. spiralis and other nematodes to the local aquatic birds. In the present study, the prevalence of $M$. spiralis collected from buff-backed heron (Ardeola ibis ibis) of Gharbia province was higher than that was previously recorded $(20-40 \%)$ by other studies $^{[1,20]}$. These variations may probably due to the locality and distribution of the intermediate host.

The present data detected that $M$. spiralis microhabitat is the proventriculus of buffbacked heron. The females are typically embedded in the gastric glands, permanently occupied the crypts of Lieberkühn, with their tails directed towards the lumen of the proventriculus. However, males are generally found on the mucosa or in the 
lumen of the proventriculus moving freely between the crypts and the lumen. This finding confirms the previous suggestion that the males move nearby spontaneously to reach and fertilize the immobile females ${ }^{[18,26]}$. The living females of $M$. spiralis that were collected from the epithelial lining of the proventricular glands in adjacent connection with their anterior ends have a red colour. The red colour may be due to the haemoglobin of the host's blood as reported in Tetrameres confuse $^{[22]}$. This finding is in agreement with the previous suggestion of Clark et al. ${ }^{[17]}$. They suggested that the presence of avian nucleated red blood cells within the alimentary canal of female Microtetrajueres sturnellae and Microtetrameres nestoris indicates that these parasites are haematophagous. In addition, Clark et al. ${ }^{[17]}$ reported that the presence of the parasite caused the destruction of glandular secretory cells of the proventriculus leading to loss of their secretory function.

The morphometric analysis of the obtained M. spiralis closely coincided with the specific characteristics described by Mahdy and El-Ghaysh ${ }^{[1]}$ except for few measurements (Tables 1 and 2). These differences may possibly be due to the different geographical locality. The length, width, and other dimensions of the studied specimens including the spicules ratio of $M$. spiralis male were within the ranges mentioned by Mahdy and El-Ghaysh ${ }^{[1]}$. However, the males have longer buccal capsule and the tail length is much greater than that defined by Mahdy and El-Ghaysh ${ }^{[1]}$. In the present study, precloacal and post cloacal papillae are two pairs, while in the study of Mahdy and El-Ghaysh ${ }^{[1]}$ the precloacal and post cloacal papillae are three pairs. The body length of $M$. spiralis females and the buccal capsule length in the current study are closely similar to the previous finding of Mahdy and El-Ghaysh ${ }^{[1]}$. The vulva located at the posterior third of the body in the current work; whereas in other study, it located at the anterior third of the $\operatorname{body}^{[1]}$.
Unfortunately, there are no available SEM descriptions to Microtetrameres sp. for comparing with the current results. Only little information is available concerning details of SEM study for genus Tetrameres. The present data detected that the buccal opening of $M$. spiralis is surrounded by two developed pseudolabia. This was correlated with Quentin et al. ${ }^{[19]}$ suggestion who reported that the sub-genus Microtetrameres has a primitive nature of its family; where Tetrameridae represented by the presence of developed pseudolabia, which resemble the cephalic structures in the Spiruridae. In Egypt, the morphological description of $M$. spiralis particularly by scanning electron microscopy is lacking. In the current study, SEM description of $M$. spiralis revealed three corrugated flowershaped processes deeply located between the two edges of each pseudolabium. The cuticular annulations have wavy margins anteriorly with numerous pointed triangular processes. Scanning electron micrographs also illustrate that the cuticle is transversely annulated with longitudinal striations near the anterior extremity of the females. In addition, numerous regularly arranged buttons-like bulges were sited. These detected structures may be have a function in obtaining blood as a food from the proventriculus glandular epithelium of the host as previously suggested $^{[27]}$. The ultrastructure at the oral opening of Tetrameres mohtedai female was interpreted as a significant structure that induced pathology in terms of laceration of the glandular epithelium and the tissue during blood feeding from the host ${ }^{[27]}$. In addition, the scanning electron micrographs of the current study revealed a single papilliform structure with central coiled projection. This structure resembled the papilliform structures at various regions of the body length of Tetrameres (Gynaecophila) aspicula, which combined tactile and secretory functions ${ }^{[24]}$. Also, it looked like the shape of the somatic papilla of the Tetrameres (Gynaecophila) spirospiculum $^{[28]}$. 


\section{CONCLUSION}

The SEM, in the current study, cleared some important characteristic features of $M$. spiralis including surface topography of adult female, the flower-shaped processes located between edges of each pseudolabium, the numerous pointed triangular processes in the anterior ridged cuticle, and the buttonlike structures that are distributed on the longitudinal striations. Further studies, by $\mathrm{X}$-ray analyses, are in progress to reveal the chemical nature of the papilla-shaped structure.

\section{ACKNOWLEDGMENTS}

This research received no specific grant from any funding agency in the public, commercial or not-for-profit sectors. The author has no potential financial conflict of interest.

\section{REFERENCES}

[1] Mahdy, A. O. and El-Ghaysh, A. (1998). Spiruroid parasites of buff backed heron (Ardeola ibis ibis) with a new species of Cordonema and Microtetrameres together with a key to the genera of Acuariidae (Seurat, 1915). Journal of the Egyptian German Society of Zoology, 27(D): 73-89.

[2] Khalifa, R. and El-Naffar, M. K. (1983). Phaneropsolus assiuticus sp.n. (Trematoda, Pleurogenidae) from birds of Upper Egypt, and remarks on representatives of the genus. Acta Parasitol Pol, 28: 369-373.

[3] Awad, A. H.; Kareem, D. K.; Al-Tameemi, I. A. A. (2014). Isolation $\&$ identification of insects \& importance some of them in infection in aquatic birds with three parasities in Basrah Province. Journal of Basrah Researches (Sciences), 40: 114-130.

[4] Kinsella, J. M. and Forrester, D. J. (2008). Tetrameridosis. In: Parasitic Diseases of Wild Birds (Atkinson, C. T.; Thomas, N. J. and Bruce Hunter, D. eds), pp. 376-383. Wiley-Blackwell, Hoboken, NJ, USA.
[5] Karstad, L. H. and Sileo, L. (1971). Cause of death in captive wild waterfowl in Kortright waterfowl park, 1967-1970. J Wild Dis, 7: 236-241.

[6] Ramaswamy, K. and Sundaram, R. K. (1981). Economic importance of Tetrameres mohtedai and Acuaria spiralis infections of fowl. Kerala Journal of Veterinary Science, 12: 255-261.

[7] Abdo, W. and Slutan, K. (2013). Histopathological findings of the kidney trematode Paratanaisia spp. (Digenea: Eucotylidae) in cattle egret (Bubulcus ibis). Rev Bras Parasitol Vet, 22(2): 12-313.

[8] Abo Essa, F. J. (2000). Role of fish eating bird ibis ibis in transmitting some parasitic larval stages to freshwater Oreochromis niloticus fish. Egypt J Agric Res, 78: 105-116.

[9] Abou Shafeey, H. E. (2012). Desportesius invaginatus (Linstow, 1901) Chabaud and Campana, 1949 (Nematoda, Acuariidae) from Ardeola ibis ibis with reference to the fine structure of the cordons. PUJ, 5: 49-57.

[10] Ammar, K. N. 2015. Surface topography of two trematodes parasites infecting grey heron Ardea cinerea Jouyi (Aves, Ciconiiformes) in Qena, Egypt. J Egypt Soc Parasitol, 45: 143152.

[11] Taeleb A. A. and Abd El-Moaty, S. M. (2011). Morphology and surface ultrastructure of Desportesius equispiculatus (Wu And Liu 1943) (Nematoda, Spirurida, Acuariidae) from the cattle egret, Ardeolaibis ibis ibis in Egypt. Egyptian Journal of Zoology, 56: 109-121.

[12] Taeleb, A. A. and Abd El-Moaty, S. M. (2014). Tegumental ultrastructure of Nephrostomum ramosum Sonsino, 1895 (Trematoda: Echinostomatidae) from Ardeola ibis ibis. African Journal of Microbiology Research, 8(18): 1916-1921.

[13] Varjabedian, K. G. (2006). An ultrastructural study on Desportesius 
invaginatus (Nematoda, Acuariidae) from Ardeola ibis ibis in Egypt. J Egypt Soc Parasitol, 36: 149-57.

[14] Wheeb, H. S.; Bazh, E. K.; Aborwash, A. et al. (2015). Some helminthes parasites infecting wild birds at Edko, Behira province, Egypt. AJVS, 47: 65-70.

[15] Anderson, R. C.; Chabaud, A. G. and Willmott, S. (2009). Keys to the Nematode Parasites of Vertebrates: Archival Volume. CABI, Wallingford, UK.

[16] Mawson P. M., (1977). The Genus Microtetrameres Travassos (Nematoda, Spirurida) in Australian Birds. South Australian Museum, Adelaide, Australia.

[17] Clark, W. C.; Black, H. and Rutherford, D. M. (1979). Microtetrameres nestoris n. $\mathrm{sp}$. (Nematoda: Spirurida), a parasite of the North Island kaka, Nestor meridionalis septentrionalis (Aves: Psittaciformes). New Zealand Journal of Zoology, 6 (DOI:10.1080/03014223. 1979.10428342).

[18] Diaz, M.; Drago F.; Nunez V. (2018). A new species of Microtetrameres (Nematoda, Tetrameridae) parasitizing Buteogallus urubitinga (Aves, Accipitridae) from northeastern Argentina. Annals of the Brazilian Academy of Sciences, 90(3): 29672976.

[19] Quentin, J. C.; Seureau, C.; Kulo, S. D. (1986). Life cycle of Tetrameres (Microtetrameres) inermis (Linstow, 1879): a tetramerid nematode parasite of the weaver Ploceus aurantius in Togo. Ann Parasitol Hum Comp, 61(3): 321-332.

[20] Hassan, M. G. and Abdel Aal, A. A. (1999). Studies on helminth parasites infesting some wild birds in Suez Canal area and Sinai
Peninsula. Assiut Vet Med J, 40(80): 103-118.

[21] Mawson P. M. (1979). Some Tetrameridae (Nematoda: Spirurida) from Australian birds. Trans R Soc S Aust 103(7): 177-184.

[22] Mollhagen, T. R. (1991). A Study of the Parasitic Nematode Genus Tetrameres. I. The Literature, 18351985. Texas Tech University, Lubbock, TX, USA.

[23] Bergan, J. F.; Radomski, A. A.; Pence, D. B. et al. (1994). Tetrameres (Petrowimeres) striata in ducks. Journal of Wildlife Diseases, 30(3): 351-358.

[24] Digiani, M. C. (2000). Tetrameres (Gynaecophila) aspicula n. sp. (Nematoda: Tetrameridae), a proventricular parasite of the whitefaced ibis Plegadis chihi in Argentina. Systematic Parasitology, 47: 111-117.

[25] Cremonte, F.; Digiani, M. C.; Bala, L.O. et al. (2001). Tetrameres (Tetrameres) megaphasmidiata $\mathrm{n}$. sp. (Nematoda: Tetrameridae), a parasite of the two-banded plover, Charadrius falklandicus, and White-rumped sandpiper, Calidris fuscicollis, from Patagonia, Argentina. Journal of Parasitology, 87:148-151.

[26] Anderson, R. C. (2000). Nematode Parasites of Vertebrates: Their Development and Transmission. CABI, Wallingford, UK.

[27] Pathak, P.; Islam, S.; Kalita, D. J. et al. (2015). Studies on Tetrameres mohtedai III: Ultrastructure of T. mohtedai. Indian Vet J, 92(3): 47-51.

[28] Digiani, M. C. and Cremonte, F. (2001). New host and locality records for Tetrameres (Gynaecophila) spirospiculum Pinto \& Vicente, 1995 (Nematoda: Tetrameridae), with new morphological data. Mem Inst Oswaldo Cruz, 96(3): 339-341.

\section{How to cite this article:}

Abou Shafeey, H. E. (2019). Scanning electron microscopy of Microtetrameres spiralis (Nematoda, Family Tetrameridae) parasitising cattle egret "Ardeola ibis ibis" in Egypt. Egyptian Journal of Zoology, 72: 57-67 (DOI: 10.12816/ejz.2019.19091.1018). 


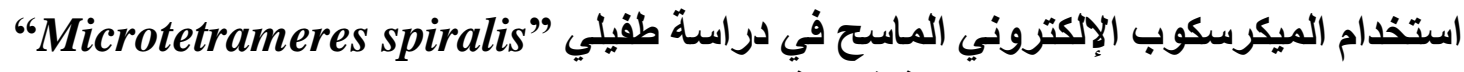

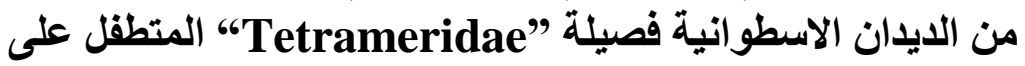

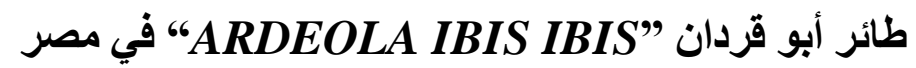

\author{
هوايدة السيد أبو شافعي
}

قسم علم الحيوان، كلية العلوم، جامعة طنطا، الغربية، جمهورية مصر العربية

يعتبر الطفيلي "Microtetrameres spiralis" من الطفيليات الثائعة التي تصيب طائر أبو قردان. ولا يوجد دراسات سابقة تُظهر التركيب الدقيق لهذا الطفيلي بواسطة المجهر الإلكتروني الماسح. ولهذا هدفت الدراسة الحالية إلى وصف الخصائص التركيبية المميزة لهذا الطفيلي باستخدام تقنيات المجهر الضوئي والمجهر الإلكتروني الماسح. وكثفت الدراسة

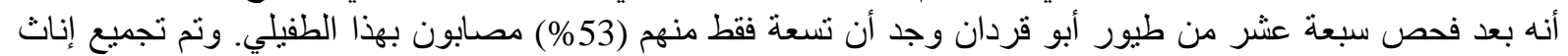

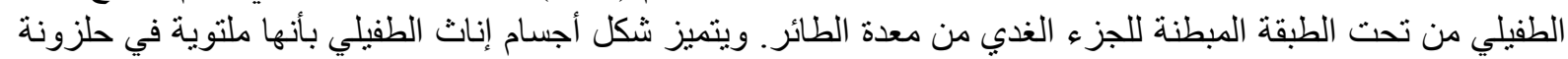

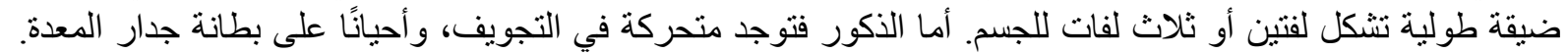

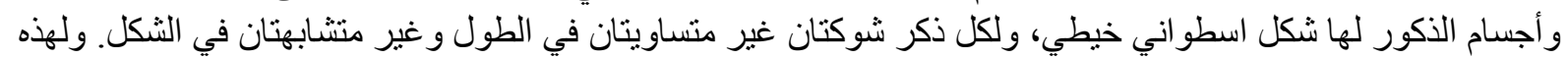

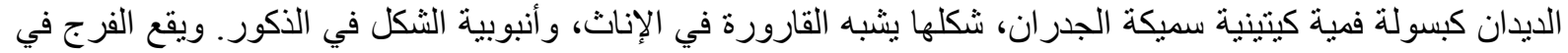
النلث الخلفي من جسم الأنثى. بالنسبة للبشرة فهي مخططة عرضيا بشكل حاد وبطول الجسم وبدون أجنحة أو أشو الك.

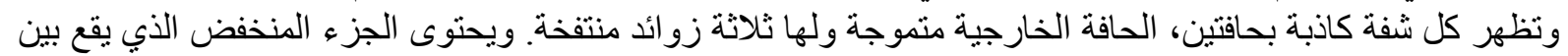

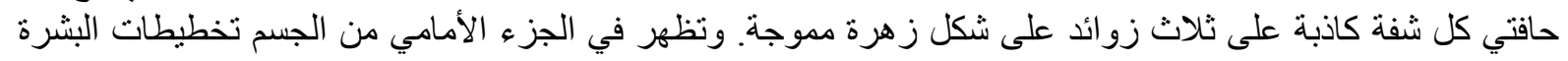

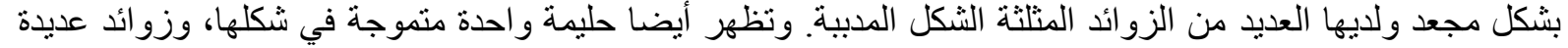

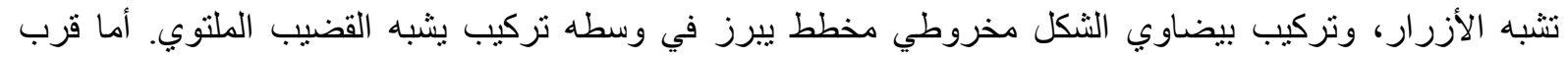
منتصف جسم الإناث فتظهر التخطيطات المستعرضة العميقة ذات الحواف الفي المتموجة. 